\title{
Is Bioavailable Vitamin D Better Than Total Vitamin D to Evaluate Vitamin D Status in Obese Children?
}

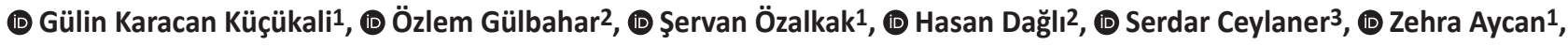 \\ (D) Şenay Savaş Erdeve1 \\ 1 University of Health Science Turkey, Dr. Sami Ulus Maternity, Child Health and Diseases Training and Research Hospital, Clinic of Pediatric \\ Endocrinology, Ankara, Turkey \\ 2 Gazi University Faculty of Medicine, Department of Clinical Biochemistry, Ankara, Turkey \\ 3Intergen Genetic Centre, Medical Geneticist, Ankara, Turkey
}

\section{What is already known on this topic?}

There is conflicting evidence about the frequency of vitamin D deficiency in obese children. In these studies, vitamin D deficiency was evaluated by measuring total vitamin D level. It is also known that vitamin D binding protein (VDBP) concentration and VDBP polymorphisms affect vitamin D level, although once again, the evidence is contradictory.

\section{What this study adds?}

While there was no difference in terms of total vitamin $\mathrm{D}$, free and bioavailable vitamin $\mathrm{D}$ levels were lower in the obese group in winter. In addition, VDBP and parathyroid hormone concentrations were found to be higher. Concentration of VDBP and VDBP polymorphism had no effect on total vitamin D level.

\begin{abstract}
Objective: Free hormones are biologically more active in target tissues. Thus, measurement of vitamin D taking into account bioavailability and free vitamin D may be preferable, especially when evidence is contradictory, as in obese children. In order to assess bioavailablity and free vitamin D, using a previously reported formula, vitamin D-binding protein (VDBP) level was measured and VDBP polymorphisms were also evaluated because of variations in binding affinity.

Methods: Eighty-four obese and 78 healthy children were included. Anthropometry, calcium, phosphorus, alkaline-phosphatase, parathyroid hormone (PTH), 25 hydroxyvitamin D [25(OH)D], bioavailable-free vitamin D, and VDBP concentration and polymorphism were evaluated in the whole group.

Results: Obese girls had significantly higher PTH than normal weight girls $(p=0.001)$. Regardless of gender, obese children had significantly higher concentrations of VDBP $(p=0.008)$ and PTH $(p=0.002)$. When samples taken in winter were analyzed, PTH and VDBP were found to be higher and bioavailable and free vitamin D lower in the obese group. There was no difference in terms of total vitamin D between groups during the winter season.

Conclusion: While total, free, and bioavailable vitamin D in the obese group was similar to the control group in autumn, free and bioavailable vitamin D in the winter was lower in the obese than the control group. In addition, PTH was higher in the obese group in both autumn and winter. Therefore, more research is needed to evaluate the variability of free and bioavailable vitamin D according to body habitus, season and the effect any differences may have.
\end{abstract}

Keywords: 25 hydroxyvitamin D, bioavailable vitamin D, free vitamin D, vitamin D binding protein, polymorphism, obesity

\section{Introduction}

Vitamin D is a pre-pro-hormone and some of its main functions are the regulation of calcium metabolism and bone homeostasis, although many more effects of vitamin $\mathrm{D}$ have been reported. Obesity, the frequency of which has been increasing in recent years, is considered a risk factor for vitamin $\mathrm{D}$ deficiency. It has been reported that vitamin
Address for Correspondence: Gülin Karacan Küçükali MD, University of Health Science Turkey, Dr. Sami Ulus Maternity, Child Health and Diseases Training and Research Hospital, Clinic of Pediatric Endocrinology, Ankara, Turkey Phone: +90 5337648426 E-mail: gulinkucukali@gmail.com ORCID: orcid.org/0000-0001-7506-1711
Conflict of interest: None declared Received: 08.10 .2020 Accepted: 23.04.2021

${ }^{\circ}$ Copyright 2021 by Turkish Pediatric Endocrinology and Diabetes Society

The Journal of Clinical Research in Pediatric Endocrinology published by Galenos Publishing House. 
D deficiency in obesity may be due to rapid metabolic clearance of vitamin D, large distribution volume and decreased bioavailability $(1,2)$. Vitamin D synthesis starts in the skin with sunlight exposure and thus a further reason for vitamin $\mathrm{D}$ deficiency in obesity may be decreased cutaneous synthesis (3). Therefore, a seasonal difference is normally observed in vitamin D levels.

25 hydroxyvitamin $\mathrm{D}[25(\mathrm{OH}) \mathrm{D}]$ is highly lipophilic and thus requires a carrier serum protein to facilitate action in the target cell. Around $85-90 \%$ of circulating $25(\mathrm{OH}) \mathrm{D}$ is bound to vitamin D-binding protein (VDBP) and 10-15\% albuminbound. Less than $1 \%$ of the circulating hormone is in free form $(4,5)$. According to the free hormone hypothesis, only hormones separated from the binding protein can enter the cell and have a biological effect (6). Bioavailable vitamin D, which is not bound to VDBP, is known to be biologically more active in the target tissues (7). VDBP concentration and VDBP polymorphism can both affect vitamin D sufficiency as both factors will change the affinity of binding to vitamin $D$. It has also been suggested that there may be a VDBP effect on $25(\mathrm{OH}) \mathrm{D}$-related intacrine responses (8). In most of the studies published to date investigating vitamin D deficiency, total vitamin D level has been measured. Some researchers have hypothesized that this total vitamin D level does not reflect the biologically active vitamin $\mathrm{D}$ available to the organism $(5,8)$. It has been suggested that the evaluation of hormonal activity and sufficiency by measuring bioavailable vitamin D will be much more reliable. The aim of this study was to evaluate whether vitamin D level was different when comparing an obese group of children with a normal weight group of children and to compare factors affecting total, bioavailable, and free vitamin D levels in both groups.

\section{Methods}

The study was performed at the pediatric endocrinology outpatient clinic of a single hospital between September 2018 and March 2019. Informed consent was taken from the families of volunteers participating in the study. The Ethics Review Board of Zekai Tahir Burak Women's Health Training and Research Hospital approved the study protocol (approval number: 16/2018, dated: 06.03.2018). The study was conducted as a University of Health Sciences' Scientific Research Coordination Unit (project number: 2018/040).

Eighty-four obese children [body mass index (BMI) $>95^{\text {th }}$ percentile] and 78 healthy children (BMI between $15^{\text {th }}$ and $85^{\text {th }}$ percentiles) without additional systemic diseases and drug-free were included in the study. Children who received vitamin D in the six months prior to the study were not included. Prepubertal cases were not included in the study.
Pubertal staging was done according to Tanner in all cases included. In girls breast stage $\geq 2$ and in males testicular volume $\geq 4 \mathrm{~mL}$ were defined as pubertal.

A SECA scale (SECA, Hamburg, Germany) and a Harpenden stadiometer (Holtain Ltd., Crymych, UK) were used to measure weight and height, respectively. Anthropometric data for the Turkish population, such as height, weight and BMI, are available in an online database (www.ceddcozum. com) (9).

Calcium, phosphorus, alkaline phosphatase (ALP), parathyroid hormone (PTH), 25(OH)D, VDBP level and VDBP polymorphism were examined in both obese and healthy groups. In addition, fasting blood glucose and insulin, hemoglobin A1c ( $\mathrm{HbA1c}$ ), total cholesterol, low density lipoprotein (LDL) cholesterol, high density lipoprotein (HDL) cholesterol, triglyceride, aspartate aminotransferase (AST), alanine aminotransferase (ALT) levels were measured only in the obese group. All measurements were made after a 10-hour fasting period. Glucose, total cholesterol, HDL cholesterol, LDL cholesterol, triglyceride, calcium, phosphorous, ALP, AST, ALT and albumin levels were measured with ready-made kits in auto-analyzer system (Beckman Coulter, Inc. USA). Serum insulin and PTH levels were measured with colorimetric method using ready-made kits. (Siemens Healthcare GmBH, Germany). HbA1c levels were measured with a ultraviolet detector using the highperformance liquid chromatography method based on the pirinciple of ion exchange chromatography.

\section{Serum Vitamin D Measurement}

Serum 25(OH)D analyses by liquid chromatography-tandem mass spectrometry were performed with a commercial kit from Recipe (Munich, Germany). That is traceable to the NIST 972a standard reference material.

\section{VDBP Measurement}

Blood samples taken from the obese and healthy control groups were centrifuged at $3000 \mathrm{~g}$ for 10 minutes. Separated serum was stored at $-80^{\circ} \mathrm{C}$ in Eppendorf tubes until analysis. All samples were melted simultaneously. Analysis was performed using commercial kits [Cloud-Clone Corp. (USCN Life Science Kit Inc.) (product number: SEB810HU) (1304 Langham Creek Dr, Suite 226, Houston, TX 77084, USA)] on an enzyme-bound immune-absorbent (ELISA) automated analyzer (Biotek, USA). This method used polyclonal VDBP antibodies. The intra-test coefficient variability $(\mathrm{CV})$ of the kit was $<10 \%$ and the inter-test CV was $<12 \%$.

Bioavailable vitamin D was calculated using the previously reported formula (4). The formula is a mathematical 
calculation model that includes VDBP and albumin binding constant.

Free vitamin $\mathrm{D}=\frac{\text { Total } 25(\mathrm{OH}) \mathrm{D}}{1+\left(6 \times 10^{5} \times \text { albumin }\right)+\left(7 \times 10^{8} \times \mathrm{VDBP}\right)}$

Bioavailable vitamin $\mathrm{D}=(\mathrm{D}$ Free $)+\left(\mathrm{D}_{\text {albumin }}\right)=(\mathrm{D}$-free $)$. $\left[\mathrm{K}_{\text {albumin }}(\mathrm{Alb})+1\right]$

\section{Polymorphism Genotyping}

However, the most common polymorphisms of the VDBP gene, which are rs4588, rs7041 and rs587776830, were studied because genotypic differences in this protein may cause significant variations in binding affinity and serum concentration.

For VDBP polymorphism, samples separated into EDTA tubes were stored at $-20^{\circ} \mathrm{C}$. DNA was isolated with a magnetic bead method (MagPurix, Zinexts, Taiwan). PCR amplification was performed using in-house designed primers. Amplicons were checked by $2 \%$ agarose gel electrophoresis. Sequencing was done by a next generation sequencing method using Miseq-Illumina equipment (Illumina, San Diego, CA, USA) in accordance with manufacturer's instructions. Data was evaluated by IGV 2.3 (Broad Institute) software (https://igv. org/).

\section{Statistical Analyses}

Descriptive statistics for continuous variables (characteristics) are presented as mean and standard deviation (SD) for normally distributed variables, as median and minimum-maximum for data not normally distributed; while categorical variables are shown as count and percent. Normality assumption of the continuous variables was tested with Kolmogov-Smirnov test. ANOVA or Student's t-test was used for comparison of means in normally distributed characteristics. However, for non-normally distributed variables, Mann-Whitney U test was performed for two groups and Kruskal-Wallis test was performed more than two groups. For determination of linear relationships among the continuous variables, Pearson correlation analysis was carried out in each group. In addition, chi-square test was also performed to determine the relationships between categorical variables. Statistical significance level was considered as $5 \%$ and Statistical Package for the Social Sciences, version 22 (IBM Inc., Armonk, NY, USA) was used for all statistical computations.

\section{Results}

There was no difference between the groups in terms of age and gender and pubertal stage $(p=0.886, p=0.309$ and $p=0.051$, respectively). In the obese group, height SD score (SDS), weight, weight SDS, BMI, and BMI SDS were significantly higher than the control group (see Table 1). When obese and control subjects were compared without gender discrimination, VDBP and PTH levels were found to be statistically higher in the obese group. Total, bioavailable and free vitamin D levels were similar in both groups. In addition, when normal weight and obese girls were compared, PTH values were found to be higher in the obese group (Table 1). Also, VDBP values were found to be nonsignificantly higher in obese girls $(p=0.057)$. No differences were detected between obese and normal weight males in these parameters. In addition, when VDBP level was compared according to the pubertal stage, there was no difference $(p=0.180)$.

In $34.5 \%(n=29)$ of the obese group and $39.7 \%(n=31)$ of the control group, $25(\mathrm{OH}) \mathrm{D}$ level was below $12 \mathrm{ng} / \mathrm{mL}$ and was considered deficient. In the obese group, PTH and HDL cholesterol were higher, and phosphorus, free and bioavailable vitamin $\mathrm{D}$ were lower in the deficient group (Table 2). Comparison of the whole obese group with the subgroup of controls $(\mathrm{n}=11)$ with normal vitamin D $[25(\mathrm{OH}) \mathrm{D}>20 \mathrm{ng} / \mathrm{mL}$ and PTH $<65 \mathrm{pg} / \mathrm{mL}$ ] is shown in Table 3. In this comparison, total, free, bioavailable vitamin D and phosphorus were lower and PTH was higher in the obese group.

Sixty-five of the obese cases were included in the study in the autumn and 19 in the winter season while 26 of the control cases were included in the study in the autumn and 52 in the winter. When only the cases included in the winter period were analyzed, PTH and VDBP were found to be higher and bioavailable and free vitamin $\mathrm{D}$ lower in the obese group (Table 4). There was no difference in terms of total vitamin $\mathrm{D}$ between groups during the winter. In autumn, phosphorus and ALP were found to be lower while PTH was higher in the obese group. When the obese group was stratified by season total, bioavailable and free vitamin $\mathrm{D}$ were lower, and VDBP was higher in the obese group in winter. Similarly, on stratification by season in the control group P, ALP, total, bioavailable and free vitamin D were found to be lower in the winter.

VDBP polymorphism distribution was similar in the obese and control groups (Table 5). In addition, calcium metabolism parameters were compared within the rs587776830, rs7041, and rs4588 genotype subgroups. There were 12 subgroups in rs587776830 genotype group and there was no difference between the groups in terms of $\mathrm{Ca}$, P, ALP, PTH, total vitamin $D$, free vitamin $D$, bioavailable vitamin $\mathrm{D}$ and VDBP (respectively $\mathrm{p}=0.457, \mathrm{p}=0.786, \mathrm{p}=0.706$, $p=0.897, p=0.125, p=0.200, p=0.239$, and $p=0.722$ ). Also, as indicated in Table 6, no difference was found in the 
rs7041 and rs4588 group in terms of calcium parameters, notably including VDBP.

In the whole group, there was positive correlation between VDBP and PTH $(p=0.009 ; r=0.20)$, negative correlation between VDBP rs4588 polymorphism and PTH $(p=0.04$; $r=-0.15)$, negative correlation between PTH $(p=0.01 ; r=-$ $0.20)$ and total $25(\mathrm{OH}) \mathrm{D}$, negative correlation between bioavailable vitamin D and PTH $(p=0.001 ; r=-0.24)$. Free vitamin D positively correlated with P, ALP, total $25(\mathrm{OH}) \mathrm{D}$ and bioavailable vitamin $\mathrm{D}(\mathrm{p}<0.001 ; \mathrm{r}=0.30$;

Table 1. Anthropometric and laboratory characteristics by gender in the obese and control groups

\begin{tabular}{|c|c|c|c|c|c|c|c|}
\hline & \multicolumn{3}{|l|}{ Female } & \multicolumn{4}{|l|}{ Male } \\
\hline & Obese $(n=54)$ & Control $(n=54)$ & $\mathrm{p}$ value & Obese $(n=30)$ & Control $(n=24)$ & $\mathrm{p}$ value & $\mathrm{p}^{*}$ value \\
\hline \multicolumn{8}{|l|}{ Median (min-max) } \\
\hline Height (cm) & $158.8 \pm 7.6$ & $152.2 \pm 10.2$ & $0.001^{\mathrm{T}}$ & $159.2 \pm 21.7$ & $165.2 \pm 12.5$ & 0.236 & $0.208^{\mathrm{T}}$ \\
\hline Height SDS & $0.6 \pm 1.08$ & $-0.1 \pm 1.08$ & $0.001^{\mathrm{T}}$ & $0.42 \pm 0.85$ & $0.05 \pm 1.13$ & 0.193 & $0.001^{\mathrm{T}}$ \\
\hline Weight (kg) & $77.9 \pm 15.2$ & $45.2 \pm 9.4$ & $0.001^{\mathrm{T}}$ & $85.9 \pm 20.5$ & $57.8 \pm 12$ & 0.001 & $0.011^{\mathrm{T}}$ \\
\hline Weight SDS & $3 \pm 0.98$ & $-0.2 \pm 0.8$ & $0.001^{\mathrm{T}}$ & $2.4 \pm 0.8$ & $-0.05 \pm 0.78$ & 0.001 & $0.001^{\mathrm{T}}$ \\
\hline BMI $\left(\mathrm{kg} / \mathrm{m}^{2}\right)$ & $30.7 \pm 4.5$ & $19.2 \pm 2.1$ & $0.001^{\mathrm{T}}$ & $32.1 \pm 5.1$ & $20.9 \pm 2.1$ & 0.001 & $0.001^{\mathrm{T}}$ \\
\hline BMI SDS & $2.7 \pm 0.6$ & $-0.1 \pm 0.6$ & $0.001^{\mathrm{T}}$ & $2.4 \pm 0.6$ & $-0.04 \pm 0.64$ & 0.001 & $0.001^{\mathrm{T}}$ \\
\hline Calcium (mg/dL) & $10.02 \pm 0.29$ & $10.01 \pm 0.37$ & $0.885^{\mathrm{t}}$ & $10.05 \pm 0.32$ & $10.14 \pm 0.28$ & 0.281 & $0.804^{\mathrm{T}}$ \\
\hline Phosphorus (mg/dL) & $4.3 \pm 0.64$ & $4.4 \pm 0.7$ & $0.597^{\mathrm{T}}$ & $4.3 \pm 0.5$ & $4.4 \pm 0.8$ & 0.636 & $0.579^{\mathrm{T}}$ \\
\hline Alkaline phosphatase (U/L) & $178 \pm 90.1$ & $209.3 \pm 125.6$ & $0.141^{\mathrm{T}}$ & $225.3 \pm 80.5$ & $220.2 \pm 118.7$ & 0.858 & $0.687^{\mathrm{t}}$ \\
\hline Albumin (g/dL) & $4.6 \pm 0.2$ & $4.5 \pm 0.2$ & $0.689^{\mathrm{T}}$ & $4.6 \pm 0.24$ & $4.7 \pm 0.32$ & 0.202 & $0.766^{\mathrm{T}}$ \\
\hline Parathyroid hormone (pg/mL) & $71 \pm 29.5$ & $54.3 \pm 19.6$ & $0.001^{\mathrm{T}}$ & $69.8 \pm 31.8$ & $59.3 \pm 28.5$ & 0.207 & $0.002^{\dagger}$ \\
\hline $25(\mathrm{OH}) \mathrm{D}(\mathrm{ng} / \mathrm{mL})$ & $16 \pm 8.5$ & $14.5 \pm 7$ & $0.303^{+}$ & $18.3 \pm 7.4$ & $15 \pm 7.1$ & 0.103 & $0.083^{+}$ \\
\hline Free vitamin $\mathrm{D}(\mathrm{pg} / \mathrm{mL})$ & $10.1 \pm 6.4$ & $9.6 \pm 4.8$ & $0.616^{\mathrm{T}}$ & $11.5 \pm 6.9$ & $9.9 \pm 4.6$ & 0.355 & $0.705^{\mathrm{T}}$ \\
\hline Bioavailable vitamin D (ng/mL) & $4.4 \pm 2.8$ & $4.1 \pm 2.1$ & $0.630^{\mathrm{p}}$ & $4.9 \pm 2.9$ & $4.3 \pm 1.9$ & 0.414 & $0.743^{+}$ \\
\hline $\begin{array}{l}\text { VDBP (mg/L) } \\
\text { Median (min-max) }\end{array}$ & $61.1(43.1-228.2)$ & $52.8(43.2-181.9)$ & $0.057 \#$ & $\begin{array}{l}67.0(43.2- \\
161.4)\end{array}$ & $49.7(43.2127 .9)$ & 0.077 & $0.008^{\#}$ \\
\hline \multicolumn{8}{|c|}{$\begin{array}{l}\text { BMI: body mass index, SDS: standard deviation (SD) score, Min-Max: minimum-maximum, VDBP: vitamin D binding protein, 25(OH)D: } 25 \text { hydroxyvitamin D. } \\
\text { 'Student's t-test was used and mean } \pm \text { SD values are given. }\end{array}$} \\
\hline
\end{tabular}

Table 2. Comparison of metabolic parameters of patients with vitamin $\mathrm{D}$ deficient and sufficient in obese group

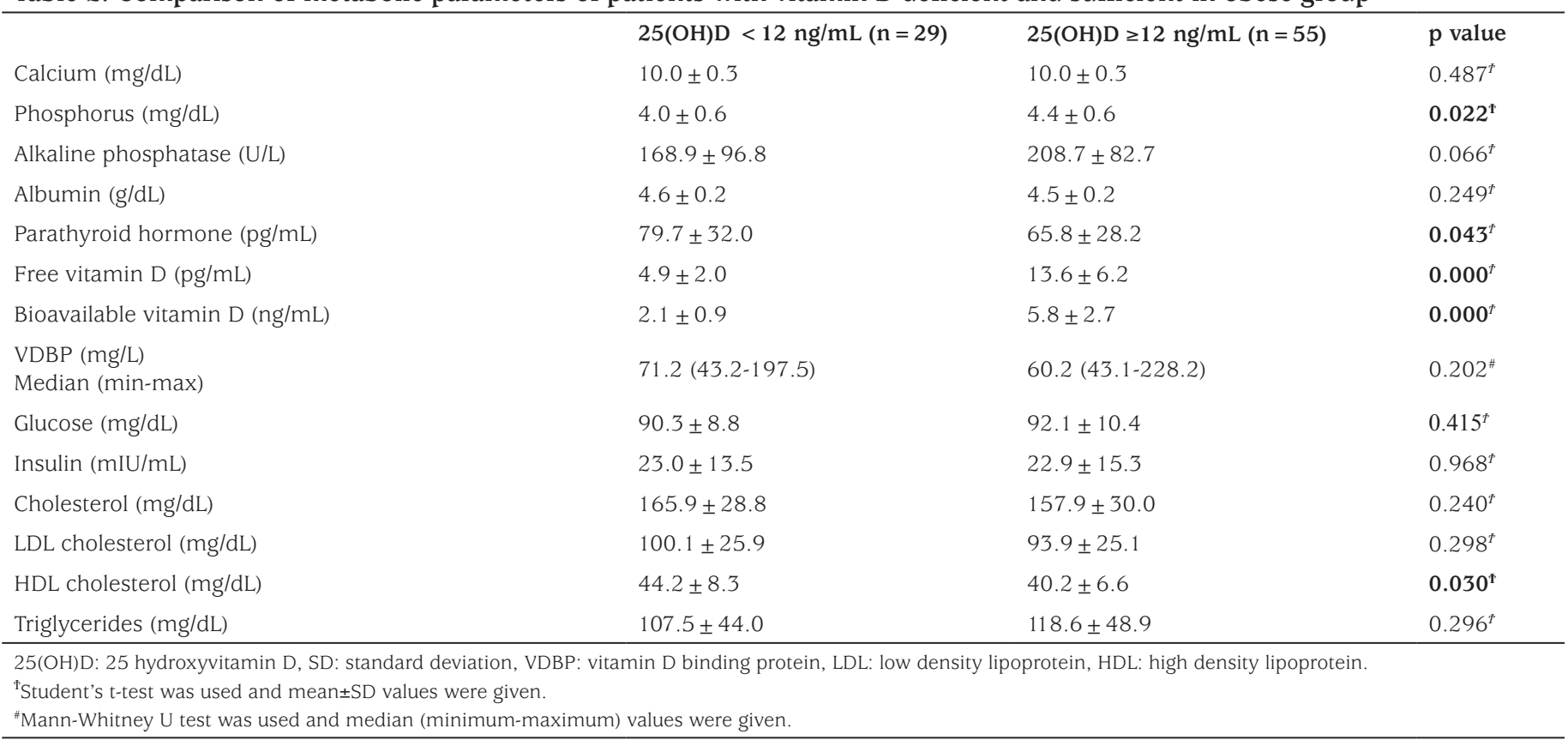


$p=0.008 ; r=0.20, p<0.001, r=0.86 ; p<0.001 ; r=0.99$, respectively), and negatively correlated with $\mathrm{PTH}$ and $\operatorname{VDBP}(p=0.001 ; r=-0.25 ; p<0.001 ; r=-0.47)$. In addition, negative correlation between bioavailable vitamin $\mathrm{D}$ and HDL cholesterol $(p=0.04 ; r=-0.21)$, positive correlation between PTH and fasting blood glucose and fasting insulin $(p<0.01 ; r=0.39 ; p=0.04 ; r=0.22$, respectively) were detected in the obese group.

\section{Discussion}

Although there have been many studies examining the relationship between obesity and vitamin $\mathrm{D}$ in children and adults, there are very few studies evaluating bioavailable vitamin D, free vitamin D and VDBP levels and VDBP polymorphism together in obese and healthy controlS $(2,10,11,12,13,14)$. Our study is the first to evaluate total, bioavailable, free vitamin D and VDBP levels and VDBP polymorphism in obese and healthy children.

In our study, total $25(\mathrm{OH}) \mathrm{D}$, bioavailable vitamin $\mathrm{D}$ and free vitamin D levels were similar in both the obese and control groups. However, considering the seasons separately, when the obese group was compared to the control group, total vitamin D was similar, bioavailable and free vitamin D levels were low, and VDBP and PTH levels were high in winter.

\begin{tabular}{|c|c|c|c|}
\hline & Obese & Control & p value \\
\hline & Whole group $(n=84)$ & Vitamin D sufficient* $(n=11)$ & \\
\hline Phosphorus (mg/dL) & $4.2(3.1-5.8)$ & $4.8(3.9-5.6)$ & 0.009 \\
\hline Alkaline phosphatase (U/L) & $198(53-394)$ & $222.5(81-362)$ & 0.367 \\
\hline Albumin (g/dL) & $4.6(4.1-5.3)$ & $4.6(4.3-4.9)$ & 0.324 \\
\hline 25(OH)D (ng/mL) & $16.4(5.1-40.8)$ & $25.9(20.2-33.1)$ & 0.000 \\
\hline Free vitamin D (pg/mL) & $8.7(1.2-35.3)$ & $15.6(7.8-24.5)$ & 0.011 \\
\hline Bioavailable vitamin D (ng/mL) & $3.7(0.5-14.6)$ & $6.8(3.3-10.6)$ & 0.010 \\
\hline VDBP (mg/L) & $62.2(43.1-228.1)$ & $81.5(43.2-181.9)$ & 0.935 \\
\hline
\end{tabular}

25(OH)D: 25 hydroxyvitamin D, VDBP: vitamin D binding protein.

*The cases with $25(\mathrm{OH}) \mathrm{D}>20 \mathrm{ng} / \mathrm{mL}$ and PTH $<65 \mathrm{pg} / \mathrm{mL}$ were defined as sufficient.

"Mann-Whitney U test was used and median (minimum-maximum) values were given.

Table 4. Comparison of calcium metabolism parameters in obese and control groups by seasons

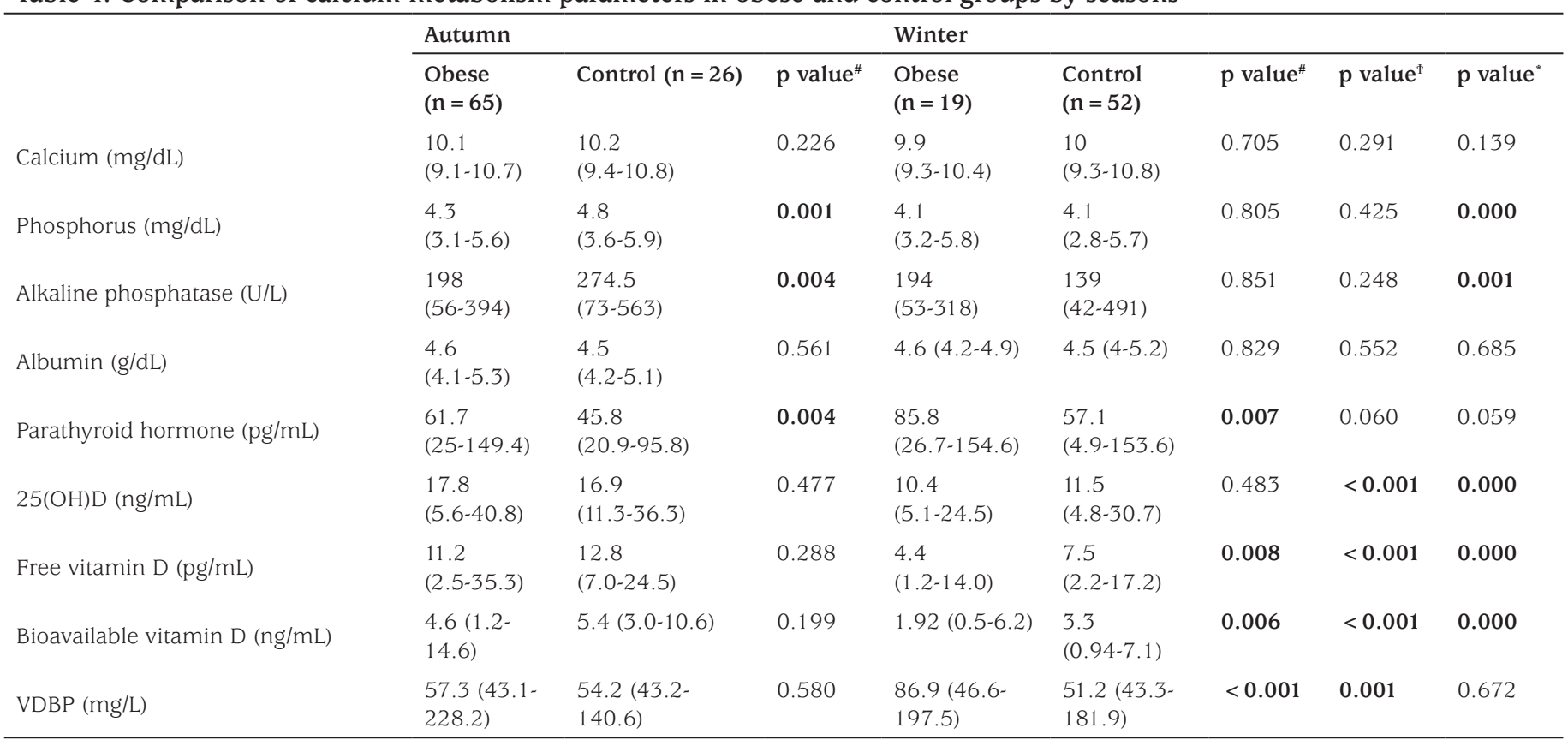

25(OH)D: 25 hydroxyvitamin D, VDBP: vitamin D binding protein.

"Mann-Whitney U test was used and median (minimum-maximum) values are given.

${ }^{\mathrm{t}}$ Comparison of the obese group by seasons.

${ }^{*}$ Comparison of the control group by seasons. 
While there was no difference in vitamin $\mathrm{D}$ and VDBP in autumn, PTH levels were higher in the obese group. Also in the obese group, while total, free, and bioavailable vitamin D were lower in winter compared to autumn, VDBP was higher and there was no difference in PTH level. Similarly, in the control group, total, bioavailable and free vitamin D were lower in winter than in autumn. In the controls VDBP and PTH did not differ between autumn and winter. We observed that all forms of vitamin D in obese and healthy children were lower in winter than in autumn.

In a study investigating the seasonal variability of vitamin $\mathrm{D}$ and PTH in obese children, vitamin D was found to be higher in summer than in autumn and winter in the obese

\begin{tabular}{|c|c|c|c|c|}
\hline SNP ID & Genotype & $\begin{array}{l}\text { Obese } \\
\text { n (\%) }\end{array}$ & $\begin{array}{l}\text { Control } \\
\mathrm{n}(\%)\end{array}$ & $\mathrm{p}$ value ${ }^{\#}$ \\
\hline VDBP rs587776830 & & & & 0.543 \\
\hline \multirow[t]{6}{*}{ VDBP rs7041 } & & & & 0.363 \\
\hline & $T T$ & $12(14)$ & $16(20)$ & \\
\hline & $T G$ & $42(50)$ & $31(40)$ & \\
\hline & $G G$ & $30(36)$ & $31(40)$ & \\
\hline & $T$ allele & $66(39)$ & $63(40)$ & \\
\hline & $G$ allele & $102(61)$ & $93(60)$ & \\
\hline \multirow[t]{6}{*}{ VDBP rs 4588} & & & & 0.256 \\
\hline & $C C$ & $56(67)$ & $46(59)$ & \\
\hline & $C A$ & $22(26)$ & $29(37)$ & \\
\hline & $A A$ & $6(7)$ & $3(4)$ & \\
\hline & $C$ allele & $134(80)$ & $121(78)$ & \\
\hline & $A$ allele & $34(20)$ & $35(22)$ & \\
\hline
\end{tabular}

SNP: single nucleotide polymorphism, VDBP: vitamin D binding protein "Pearson $\chi^{2}$ test was used. and control groups. In addition, seasonal variability was not detected in the obese group in terms of PTH, while it was found to be high in the control group in autumn and spring months (3). Seasonal variation in vitamin D was evaluated in a study conducted in the UK that included 223 obese, overweight and normal weight adults (2). The level of vitamin $\mathrm{D}$ in the obese and overweight groups was found to be lower than in normal weight in autumn and spring, but similar to those of normal weight in winter. Also, it has been concluded that the synthesis of vitamin D in the skin is similar in obese and normal weight individuals. One study reported in 2015, with 63 obese and 21 healthy children aged 4-15 years, that total $25(\mathrm{OH}) \mathrm{D}$ was lower in the obese group than in the non-obese group, but no difference was found between bioavailable vitamin D and the PTH levels, regardless of the season (11). In our study, in the obese group vitamin D levels were similar to the control group and PTH was higher than the control group in autumn. In winter, the total vitamin D level in the obese group was similar to the control group, free and bioavailable vitamin D was lower than the control group, and VDBP and PTH were higher than the control group.

In the present study, Ca, P, ALP and albumin levels were similar in the obese and healthy control group, whereas PTH levels were higher in the obese group. Vitamin D deficiency is known to be associated with decreased calcium absorption and increased PTH $(5,15)$. PTH is also thought to be a useful indicator of the biological significance of low vitamin D level (16). In a study involving 595 female adult patients, $25(\mathrm{OH}) \mathrm{D}, \mathrm{PTH}$ and VDBP levels were measured and VDBP GC phenotyping was performed. Similar to our study, an inverse relationship was found between $25(\mathrm{OH})$ D and PTH. The patients with Gc1-1 phenotype and 25(OH)

\begin{tabular}{|c|c|c|c|c|c|c|c|}
\hline & \multicolumn{4}{|l|}{ rs7041 } & \multicolumn{3}{|l|}{ rs 4588} \\
\hline & GG $(n=61)$ & TT $(n=28)$ & TG $(n=73)$ & $\mathrm{p}$ value & $C C(n=102)$ & CA $(n=51)$ & $p$ value \\
\hline Phosphorus (mg/dL) & $4.3 \pm 0.6$ & $4.3 \pm 0.7$ & $4.3 \pm 0.7$ & $0.796^{\mathrm{t}}$ & $4.3 \pm 0.7$ & $4.2 \pm 0.6$ & $0.283^{\varphi}$ \\
\hline Alkaline phosphatase (U/L) & $206.1 \pm 103.7$ & $223.9 \pm 117.8$ & $193.4 \pm 105.2$ & $0.416^{\mathrm{T}}$ & $201.7 \pm 104.9$ & $195.3 \pm 104.5$ & $0.747^{\varphi}$ \\
\hline 25(OH)D (ng/mL) & $15.8 \pm 7.9$ & $15.8 \pm 7.9$ & $15.8 \pm 7.5$ & $0.992^{\mathrm{T}}$ & $16.5 \pm 8.2$ & $14.9 \pm 6.7$ & $0.381^{\varphi}$ \\
\hline Free vitamin D (pg/mL) & $10.4 \pm 5.8$ & $9.3 \pm 5$ & $10.3 \pm 6$ & $0.808^{\mp}$ & $10.7 \pm 6.1$ & $9.5 \pm 5.2$ & $0.337^{\varphi}$ \\
\hline Bioavailable vitamin D (ng/mL) & $4.43 \pm 2.47$ & $4 \pm 2.2$ & $4.4 \pm 2.6$ & $0.856^{\mathrm{t}}$ & $4.6 \pm 2.6$ & $4.13 \pm 2.3$ & $0.367^{\varphi}$ \\
\hline $\begin{array}{l}\text { VDBP (mg/L) } \\
\text { Median (min-max) }\end{array}$ & $\begin{array}{l}52.8 \\
(43.2-181.2)\end{array}$ & $\begin{array}{l}71.0 \\
(43.2-153.2)\end{array}$ & $\begin{array}{l}57.3 \\
(43.1-228.2)\end{array}$ & $0.111^{\#}$ & $\begin{array}{l}56.9 \\
(43.1-228.2)\end{array}$ & $\begin{array}{l}56.5 \\
(43.1-197.4)\end{array}$ & $0.4221^{\lambda}$ \\
\hline
\end{tabular}


$\mathrm{D}<40 \mathrm{nmol} / \mathrm{L}$ had higher PTH levels but when all patients were included in the evaluation, in terms of PTH, it has been reported that there was no difference according to Gc phenotypes (17). In our study, a negative correlation between VDBP rs4588 polymorphism and PTH suggested that VDBP polymorphisms may affect PTH levels.

Our findings showed that the VDBP level was significantly higher in the obese group than in the control group. VDBP is the major serum transport protein of vitamin $D(18)$. VDBP also facilitates the transport of $25(\mathrm{OH}) \mathrm{D}$ to tissues and regulates its bioavailability (19). In our study, total $25(\mathrm{OH}) \mathrm{D}$, bioavailable and free vitamin D levels were similar between the two groups, while PTH and VDBP were increased in the obese group. There was no difference between the groups in terms of pubertal stages. In a study conducted in 15 obese and 15 normal weight adults between the ages of 20-35, the VDBP level was reported to be higher in the obese group (18). In a study performed in 2014 comparing 43 obese and 43 normal-weight women aged 22-45 years VDBP levels were found to be higher in the obese group (20). It has been stated that high estrogen levels in obese women increase the hepatic production of VDBP. However, in our study, there was no difference in VDBP by gender in the whole group. Similarly, in another study conducted in adults, VDBP and PTH were higher in the obese group (14). In our study, the positive correlation between VDBP and PTH in the whole group, independent of vitamin D, suggested that these two variables may be related to each other.

The binding affinity of $25(\mathrm{OH}) \mathrm{D}$ to VDBP can change according to VDBP polymorphism and its level may be affected (8). In our study, the distribution of VDBP polymorphism in the obese group was similar to the control group. According to polymorphisms, there was no difference in terms of $25(\mathrm{OH}) \mathrm{D}$, bioavailable vitamin $\mathrm{D}$, free vitamin $\mathrm{D}$ and VDBP. Contrary to our results, in many studies, it has been shown that total vitamin D, free vitamin D and VDBP levels are lower in the Gc2 genotype $(21,22,23,24,25,26)$. The reason why there was no difference in our study may be due to the low number of our cases compared to other studies or it has been examined in different ethnicity.

In our study, a negative correlation was found between total 25(OH)D, bioavailable, free vitamin D and PTH. Similarly, in the literature it was reported that a negative correlation was found between PTH and total 25(OH)D and bioavailable vitamin $\mathrm{D}$ in a study investigating cases with chronic renal failure between the ages of 5-21 years (27). In another study examining 94 dialysis patients in adulthood, a negative correlation was found between bioavailable vitamin D and $\mathrm{PTH}$, while no correlation was found between total $25(\mathrm{OH})$
D and PTH (28). In another study of adults, it was reported that a negative correlation was found between total vitamin D and free vitamin D and PTH in women and men, and, in women only, a negative correlation was found between bioavailable vitamin D and PTH (14).

There are publications showing that vitamin D status is associated with many diseases, such as obesity, insulin resistance (IR), diabetes, dyslipidemia, atherosclerosis and cancer, in addition to regulating intestinal calcium absorption and bone homeostasis. In our study, negative correlations between bioavailable vitamin D and HDL cholesterol, and positive correlations between fasting blood glucose, fasting insulin and PTH were found in the obese group. There are studies reporting negative correlation between total vitamin D level and fasting glucose levels (12), positive correlation between total and free vitamin $\mathrm{D}$ and insulin sensitivity, and negative correlation with homeostasis model assessment of IR (29), and negative correlation between free vitamin D and fasting blood glucose (30). There are also studies reporting positive correlation between VDBP and total cholesterol, LDL cholesterol and triglycerides (31). In light of these data, it is apparent that vitamin D and PTH play an effective part in metabolic balance.

\section{Study Limitations}

The dietary calcium and vitamin D intakes could not be evaluated. The clothing characteristics, skin pigmentation and the time spent outside were not investigated in any study subjects.

\section{Conclusion}

It was found that total, bioavailable and free vitamin D levels in the obese group were similar to the control group. Our results suggest that VDBP level and VDBP polymorphism may have a direct effect on PTH regulation. However, when the obese and control groups in winter were compared, there was no difference in total vitamin D, while free and bioavailable vitamin D was lower and PTH and VDBP was higher in obese children. More research is needed to explain the variability of total, free and bioavailable vitamin D according to seasons.

\section{Acknowledgements}

We wish to express our gratitude to the parents and the patients who participated in this study.

\section{Ethics}

Ethics Committee Approval: The Ethics Review Board of Zekai Tahir Burak Women's Health Training and Research 
Hospital approved the study protocol (approval number: 16/2018, dated: 06.03.2018).

Informed Consent: Informed consent was taken from the families of volunteers participating in the study.

Peer-review: Externally peer-reviewed.

\section{Authorship Contributions}

Surgical and Medical Practices: Gülin Karacan Küçükali, Şervan Özalkak, Serdar Ceylaner, Zehra Aycan, Şenay Savaş Erdeve, Concept: Gülin Karacan Küçükali, Zehra Aycan, Şenay Savaş Erdeve, Design: Gülin Karacan Küçükali, Zehra Aycan, Şenay Savaş Erdeve, Data Collection or Processing: Gülin Karacan Küçükali, Özlem Gülbahar, Şervan Özalkak, Hasan Dağlı, Serdar Ceylaner, Analysis or Interpretation: Özlem Gülbahar, Hasan Dağlı, Serdar Ceylaner, Şenay Savaş Erdeve, Literature Search: Gülin Karacan Küçükali, Şenay Savaş Erdeve, Writing: Gülin Karacan Küçükali, Şenay Savaş Erdeve.

Financial Disclosure: The study was conducted as a University of Health Sciences' Scientific Research Coordination Unit (project number: 2018/040).

\section{References}

1. Drincic AT, Armas LAG, Diest EEV, Heaney RP. Wolumetric dilution, rather than sequestration best explains the low vitamin $D$ status of obesity. Obesity (Silver Spring) 2012;20:1444-1448. Epub 2012 Jan 19

2. Walsh JS, Evans AL, Bowles S, Naylor KE, Jones KS, Schoenmakers I, Jacques RM, Eastell R. Free 25-hydroxyvitamin D is low in obesity, but there are no adverse associations with bone health. Am J Clin Nutr 2016;103:1465-1471. Epub 2016 May 11

3. Durá-Travé T, Gallinas-Victoriano F, Malumbres-Chacon M, AhmedMohamed L, Chueca-Guindulain MJ, Berrade-Zubiri S. Are there any seasonal variations in 25-hydroxyvitamin $\mathrm{D}$ and parathyroid hormone serum levels in children and adolescents with severe obesity? Eur J Pediatr 2021;180:1203-1210. Epub 2020 Nov 4

4. Bikle DD, Siiteri PK, Ryzen E, Haddad JG. Serum protein binding of 1,25-dihydroxyvitamin $\mathrm{D}$ : a reevaluation by direct measurement of free metabolit levels. J Clin Endocrinol Metab 1985;61:969-975

5. Powe CE, Ricciardi C, Berg AH, Erdenesanaa D, Collerone G, Ankers E, Wenger J, Karumanchi SA, Thadhani R, Bhan I. Vitamin D-binding protein modifies the vitamin D-bone mineral density relationship. J Bone Miner Res 2011;26:1609-1616.

6. Mendel CM. The free hormone hypothesis: a physiologically based mathematical model. Endocr Rev 1989;10:232-274.

7. Yao P, Sun L, Lu L, Ding H, Chen X, Tang L, Xu X, Liu G, Hu Y, Ma $\mathrm{Y}$, Wang $\mathrm{F}$, Jin $\mathrm{Q}$, Zheng $\mathrm{H}$, Yin $\mathrm{H}$, Zeng $\mathrm{R}$, Chen $\mathrm{Y}$, Hu FB, Li H, Lin $\mathrm{X}$. Effects of genetic and nongenetic factors on total and Bioavailable 25(OH)D responses to Vitamin D Supplementation. J Clin Endocrinol Metab 2017;102:100-110.

8. Chun RF, Peercy BE, Orwoll ES, Nielson CM, Adams JS, Martin H, Vitamin D and DBP: the free hormone hypothesis revisited. J Steroid Biochem Mol Biol 2014;144:132-137. Epub 2013 Oct 4

9. Neyzi O, Bundak R, Gökçay G, Günöz H, Furman A, Darendeliler F, Baş F. Reference values for weight, height, head circumference, and body mass index in turkish children. J Clin Res Pediatr Endocrinol 2015;7:280-293.

10. Bilici ME, Savaş Erdeve Ş, Çetinkaya S, Aycan Z. The effect of 2000 IU/ day vitamin D supplementation on insülin resistance and cardiovascular risk parameters in vitamin D deficient obese adolescents. Turk J Pediatr 2019;61:723-732.

11. Miraglia del Giudice E, Grandone A, Cirillo G, Capristo C, Marzuillo P, Di Sessa A, Umano GR, Ruggiero L, Perrone L. Bioavailable vitamin D in obese children: the role of insulin resistance. J Clin Endocrinol Metab 2015;100:3949-3955. Epub 2015 Aug 28

12. Pelczynska M, Grzelak T, Sperling M, Bogdanski P, Musialik DP, Czyzewska K. Impact of 25-hydroxyvitamin D, free and bioavailable fractions of vitamin D, and vitamin D binding protein levels on metabolic syndrome components. Arch Med 2017;13:745-752. Epub 2016 Mar 16

13. Naderpoor N, Shorakae S, Abell SK, Mousa A, Joham AE, Moran LJ, Stepto NK, Spritzer PM, Teede HJ, de Courten B. Bioavailable and free 25-hydroxyvitamin $\mathrm{D}$ and vitamin $\mathrm{D}$ binding protein in polycystic ovary syndrome: Relationships with obesity and insulin resistance. J Steroid Biochem Mol Biol 2018;177:209-215. Epub 2017 Jul 19

14. Saarnio E, Pekkinen M, Itkonen ST, Kemi V, Karp H, Ivaska KK, Risteli J, Koivula MK, Kärkkäinen M, Mäkitie O, Sievänen H, Lamberg-Allardt C. Low free 25-hydroxyvitamin D and high vitamin D binding protein and parathyroid hormone in obese Caucasians. A complex association with bone? PLoS One 2018;13:e0192596.

15. Chun RF, Shieh A, Gottlieb C, Yacoubian V, Wang J, Hewison M, Adams JS. Vitamin D binding protein and the biological activity of vitamin D. Front Endocrinol (Lausanne) 2019;10:718. Epub 2008 Jan 4

16. Goldner WS, Stoner JA, Thompson J, Taylor K, Larson L, Erickson J, McBride C. Prevalence of vitamin D insufficiency and deficiency in morbidly obese patients: a comparison with non-obese controls. Obes Surg 2008;18:145-150.

17. Lauridsen AL, Vestergaard P, Hermann AP, Brot C, Heickendorff L, Mosekilde L, Nexo E. Plasma concentrations of 25-hydroxy-vitamin $\mathrm{D}$ and 1,25-dihydroxy-vitamin $\mathrm{D}$ are related to the phenotype of Gc (vitamin D-binding protein): a cross-sectional study on 595 early postmenopausal women. Calcif Tissue Int 2005;77:15-22. Epub 2005 May 5

18. Oberbach A, Blüher M, Wirth H, Till H, Kovacs P, Kullnick Y, Schlichting N, Tomm JM, Rolle-Kampczyk U, Murugaiyan J, Binder H, Dietrich A, von Bergen $\mathrm{M}$. Combined proteomic and metabolomic profiling of serum reveals association of the complement system with obesity and identifies novel markers of body fat mass changes. J Proteome Res 2011;10:4769-4788. Epub 2011 Aug 29

19. Powe CE, Evans MK, Wenger J, Zonderman AB, Berg AH, Nalls $M$, Tamez H, Zhang D, Bhan I, Karumanchi SA, Powe NR, Thadhani R. Vitamin D-binding protein and vitamin D status of black Americans and white Americans. N Engl J Med 2013;369:1991-2000.

20. Karlsson T, Osmancevic A, Jansson N, Hulthen L, Holmang A, Larsson I. Increased vitamin D-binding protein and decreased free $25(\mathrm{OH}) \mathrm{D}$ in obese women of reproductive age. Eur J Nutr 2014;53:259-267. Epub 2013 Apr 21

21. Shao B, Jiang S, Muyiduli X, Wang S, Mo M, Li M, Wang Z, Yu Y. Vitamin D pathway gene polymorphisms influenced vitamin D level among pregnant women. Clin Nutr 2018;37:2230-2237.

22. Schwartz JB, Gallagher JC, Jorde R, Berg V, Walsh J, Eastell R, Evans AL, Bowles S, Naylor KE, Jones KS, Schoenmakers I, Holick M, Orwoll E, Nielson C, Kaufmann M, Jones G, Bouillon R, Lai J, Verotta D, Bikle D. Determination of Free 25(OH)D Concentrations and Their Relationships to Total 25(OH)D in Multiple Clinical Populations. J Clin Endocrinol Metab 2018;103:3278-3288. 
23. Hoofnagle AN, Eckfeldt JH, Lutsey PL. Vitamin D-binding protein concentrations quantified by mass spectrometry. N Engl J Med 2015;373:1480-1482. Epub 2015 Sep 23

24. Carpenter TO, Zhang JH, Parra E, Ellis BK, Simpson C, Lee WM, Balko J, Fu L, Wong BY, Cole DE. Vitamin D binding protein is a key determinant of 25-hydroxyvitamin D levels in infants and toddlers. J Bone Miner Res 2013;28:213-221.

25. Santos BR, Mascarenhas LP, Boguszewski MC, Spritzer PM. Variations in the vitamin D-binding protein (DBP) gene are related to lower 25-hydroxyvitamin D levels in healthy girls: a cross-sectional study. Horm Res Paediatr 2013;79:162-168. Epub 2013 Mar 20

26. Lauridsen AL, Vestergaard P, Hermann AP, Brot C, Heickendorff L, Mosekilde L, Nexo E. Plasma concentrations of 25-hydroxy-vitamin $\mathrm{D}$ and 1,25-dihydroxy-vitamin $\mathrm{D}$ are related to the phenotype of Gc (vitamin D-binding protein): a cross-sectional study on 595 early postmenopausal women. Calcif Tissue Int 2005;77:15-22. Epub 2005 May 5

27. Denburg MR, Kalkwarf HJ, de Boer IH, Hewison M, Shults J, Zemel BS, Stokes D, Foerster D, Laskin B, Ramirez A, Leonard MB. Vitamin
D bioavailability and catabolism in pediatric chronic kidney disease. Pediatr Nephrol 2013;28:1843-1853. Epub 2013 Jun 2

28. Bhan I, Powe CE, Berg AH, Ankers E, Wenger JB, Karumanchi SA, Thadhani RI. Bioavailable vitamin D is more tightly linked to mineral metabolism than total vitamin $\mathrm{D}$ in incident hemodialysis patients. Kidney Int 2012;82:84-89. Epub 2012 Mar 7

29. Lee CC, Young KA, Norris JM, Rotter JI, Liu Y, Lorenzo C, Wagenknecht LE, Cole DE, Haffner SM, Chen YI, Hanley AJ. Association of directly measured plasma free $25(\mathrm{OH}) \mathrm{D}$ with insulin sensitivity and secretion: The IRAS family study. J Clin Endocrinol Meta 2017;102:2781-2788.

30. Altinova AE, Ozkan C, Akturk M, Gulbahar O, Yalcin M, Cakir N, Toruner FB. Vitamin D-binding protein and free vitamin D concentrations in acromegaly. Endocrine 2016;52:374-379. Epub 2015 Nov 7

31. Speeckaert MM, Taes YE, Buyzere MLD, Christophe AB, Kaufman JM, Delanghe JR. Investigation of the potential association of vitamin $D$ binding protein with lipoproteins. Ann Clin Biochem 2010;47:143-150. Epub 2010 Feb 9 